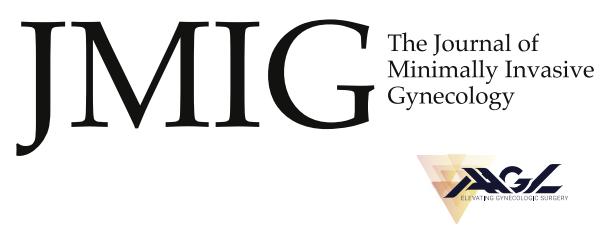

Original Article

\title{
What is the Best Surgeon's Knot? Evaluation of the Security of the Different Laparoscopic Knot Combinations
}

\author{
Armando Romeo, BE, Claudia Lima Rocha, MD, Luiz Flavio Fernandes, MD, \\ Fernanda de Almeida Asencio, MD, Monica Tessmann Zomer, MD, Christiane Fujimoto, MD, \\ Anastasia Ussia, MD, Arnaud Wattiez, MD, PhD, Philippe Robert Koninckx, MD, PhD, and \\ William Kondo, MD
}

From the Department of Gynecology, Santa Casa University, São Paulo, Brazil (Drs. Romeo and Fujimoto), Karl Storz of South America, São Paulo, Brazil (Dr. Romeo), Department of Gynecology, Federal University of São Paulo, São Paulo, Brazil (Dr. Rocha), Department of Gynecology, University of São Paulo, São Paulo, Brazil (Dr. Fernandes), Gynecologic Endoscopy Section, Department of Obstetrics and Gynecology, Santa Casa de São Paulo Hospital, São Paulo, Brazil (Dr. Asencio), Department of Gynecology, Sugisawa Hospital, Curitiba, Brazil (Drs. Zomer and Kondo), Gruppo Italo Belga, Villa del Rosario and Gemelli Hospitals, Catholic University of the Sacred Heart, Rome, Italy (Dr. Ussia), Department of Gynecology, University of Strasbourg, France and Latifa Hospital, Dubai, United Arab Emirates (Dr. Wattiez), and Department of Obstetrics and Gynecology, Catholic University of Leuven, Leuven, Belgium (Dr. Koninckx).

ABSTRACT Study Objective: To investigate the security of various knot combinations in laparoscopic surgery.

Design: Prospective nonrandomized trial (Canadian Task Force classification II).

Setting: Storz Training Centre, Sao Paulo, Brazil.

Intervention: Different knot combinations $(\mathrm{n}=2000)$ were performed in a laparoscopic trainer. Dry or wet 2.0 polyglycolic acid or dry 2-0 poliglecaprone 25 was used. The tails were cut at $10 \mathrm{~mm}$, and the loops were tested in a dynamometer. The primary endpoints were the forces at which the knot combination opened or at which the suture broke. Resulting tail lengths were measured.

Measurements and Main Results: Surprisingly, the combination of a 2-throw half knot (H2) and a symmetric 1-throw half knot (H1s) (a surgical flat knot) opened at $<1$ Newton $(\mathrm{N})$ in $2.5 \%$ of tests and at $<10 \mathrm{~N}$ in $5 \%$ of tests. This occasional opening at low forces persisted after 1 or 2 additional H1s knots. A sequence of an $\mathrm{H} 2$ or a 3-throw half knot (H3) followed by a $\mathrm{H} 2$, either symmetric or asymmetric $(\mathrm{H} 2 \mathrm{H} 2$ or $\mathrm{H} 3 \mathrm{H} 2)$, resulted in $100 \%$ secure knots that never opened at forces below $30 \mathrm{~N}$. Other safe combinations were $\mathrm{H} 2 \mathrm{H} 1$ s followed by 2 blocking half hitches, and a sequence of 5 half hitches with 3 blocking sequences.

Conclusion: A traditional surgical knot ( $\mathrm{H} 2 \mathrm{H} 1 \mathrm{~s})$ occasionally opens with little force and thus is potentially dangerous. Safe knots are $\mathrm{H} 2 \mathrm{H} 2$ and $\mathrm{H} 3 \mathrm{H} 2$ combinations, a sequence of 5 half hitches with 3 blocking sequences, and $\mathrm{H} 2 \mathrm{H} 1 \mathrm{~s}$ together with 2 blocking half hitches. Journal of Minimally Invasive Gynecology (2018) 25, 902-911 (C) 2018 AAGL. All rights reserved.

Keywords: $\quad$ Knots; Knot security; Knot tying; Surgery; Suturing

Suturing comprising stitching and knot tying is a basic surgical skill. The surgeon determines the knot combinations and sutures to use. Sutures can be monofilament or multifilament with varying elasticity, ease of handling, rate of resorption, security, tensile strength over time, and severity and duration of the inflammatory reaction [1].

The authors declare that they have no conflicts of interest.

Corresponding author: Philippe Robert Koninckx, MD, PhD, Vuilenbos 2, 3360, Bierbeek, Belgium.

E-mail: pkoninckx@gmail.com

Submitted November 23, 2017. Accepted for publication January 27, 2018. Available at www.sciencedirect.com and www.jmig.org
Knot tying used to be based on education resulting from a combination of surgical experience and knowledge of seamen, fishermen, weavers, and hangmen [2], with more than 250 different knots described. More recently, different knot combinations with different suture materials have been described, but many discrepancies in nomenclature, testing methods, and in the type of data reported persist [3]. Knot security was defined as a knot combination that does not untie or slip open [4] before the suture line breaks [1,5] or that does not slip by $>3 \mathrm{~mm}$ [6-8]. With the introduction of tensiometers, knot security became defined as the maximum load sustained before the occurrence of knot slippage, knot 
failure, or suture failure by breaking $[1,9,10]$. Recently, resistance to cyclic loading besides monotonic loading has been described in orthopedic surgery $[6,7,11,12]$. An increasing number of knots and throws increases the security of a knot combination, but also increases the amount of foreign material and the duration of resorption. Therefore, in surgery, it is important to use a knot combination with the minimum number of knots and throws required for a sufficiently secure knot. Unfortunately, however, published data are not clear. The use of more than 4 throws does not necessarily increase security, whereas Schaaf et al [13] reported that 4 throws are the minimum number for a secure knot when using polydioxanone suture. Marturello et al [1] tested 5 different sutures (polyglactin 910, Ethilon, polyglytone 6211, Surgipro, and MonoSbf) in flat knot combinations and found that knots with 3 throws were as secure as knots with 6 throws. Schubert et al [14] found more knot failures with 6 blocking half hitches than with 6-throw flat knots using 0-0 monofilament suture. Amortegui and Restrepo [15] reported that 6-throw knots had no failures and were more secure than 4-throw knots. The security of various combinations of half hitches, half knots, and complex sliding knots [12] with different number of throws has been evaluated [5,12,16-28], but in the absence of a systematic evaluation of all possible combinations, the conclusions remain unclear. Finally, studies of knot security following hand or laparoscopic tying have examined the forces of individual knot tying, which are lower with laparoscopic tying. The emerging conclusion is that a correct knot combination is even more important during laparoscopic suturing $[15,16]$, given the lower knot tying forces.

The exact forces required to hold tissues together in gynecologic surgery are not well documented; however, they likely are much lower than those in palatal surgery [29] and in orthopedic surgery, in which a secure knot should show resistance to forces up to $120 \mathrm{~N}$ in cyclic testing [12,30,31].

Laparoscopic knot tying requires proper training and education [32-37]. In 1984, Trimbos reported an overall lack of knowledge of knot tying [24], whereas in 1975, Thacker et al [21] found that only $25 \%$ of the surgeons used adequate knot combinations. The proportion of secure knots was $73 \%$ by experienced surgeons, compared with $59 \%$ by fourthyear veterinary students.

Some occasional complications after surgery may be related to unsecure knots. Although difficult to prove, this has been speculated when discussing the occasional opening of a vaginal cuff, the detachment of mesh after a promontofixation, bleeding from a uterine artery, or early intestinal anastomosis leakage. Because knot security is more important for running sutures, this may unconsciously have contributed to the discussions of whether to close the vaginal cuff [38-41] or a bowel wall with a continuous suture or interrupted stitches $[22,42]$. Unfortunately, rare events are difficult to investigate; indeed, the occurrence of 10 complications in $1 \%$ requires a prohibitively large number of 1000 interventions.
Consequently, we decided to systematically evaluate the security of different knot combinations. Moreover, based on observations during training sessions on knot tying, we had the impression that identical knot combinations occasionally behaved differently.

\section{Materials and Methods}

\section{Knot Classification and Abbreviations Used}

A knot can be a half knot (H) or a half hitch (S) (Fig. 1). A half knot, also called a square or flat knot, results when both ends are pulled in the same direction as the threads entering and leaving the knot. A half hitch, also called a sliding knot, occurs when the traction is made on one end of the suture only while the other active end with the knot slides freely around the passive end. The active end thus is pulled in the opposite direction as the suture entering the knot. A half knot can be formed by 1,2, or 3 throws. A half hitch always has 1 throw. In sequences of half knots, the rotation of a knot can be the same (symmetric) or the opposite (asymmetric) as the previous knot. In a symmetric second half knot (Fig. 1A), the tails are in the same plane as those entering the first half knot. When the tails are in a perpendicular plane, the second half knot is asymmetric (Fig. 1B). When half hitches are combined, the second half hitch can be sliding (Fig. 1C) when the passive thread remains the same or blocking when the passive thread is changed (Fig. 1D). We recently

\section{Fig. 1}

(A and B) Symmetric (A) and asymmetric (B) sequences of 2 singlethrow half knots. (C and D) A sliding sequence (C) and a blocking sequence (D) of 2 half hitches. (D and E) Final knot combination of half hitches and a secure 3-throw half knot followed by a symmetric 2-throw half knot.

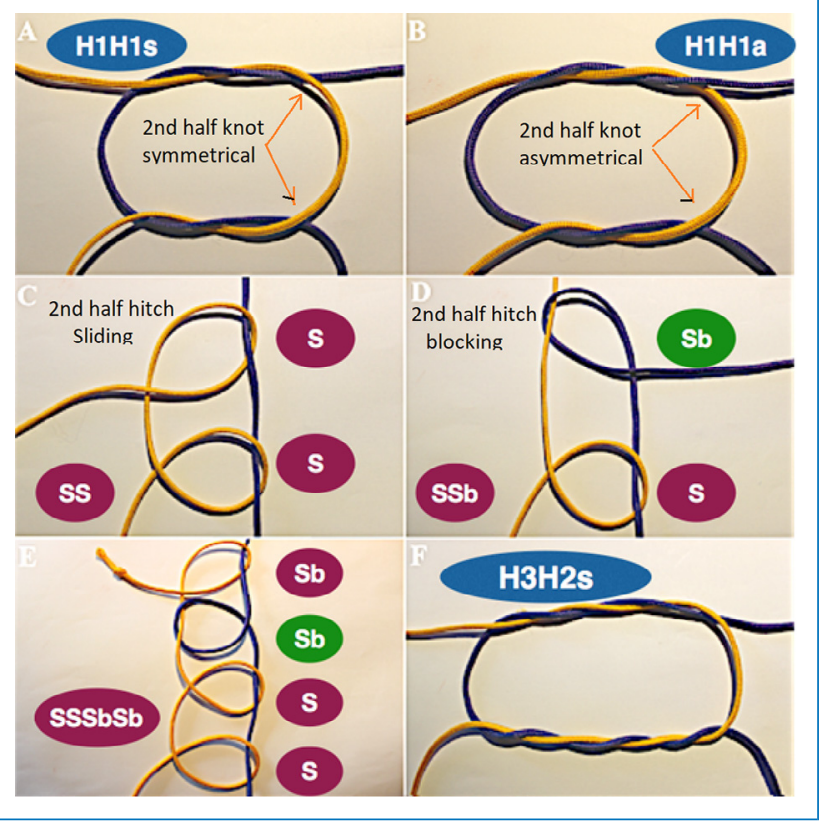


demonstrated how to perform some of these blocking sequences in a video article [43].

Sequences of half knots are referenced as " $\mathrm{H}$ " followed by the number of throws $(1,2$, or 3$)$, and from the second knot by the rotation compared with the previous knot, which can be symmetric (s) or asymmetric (a) (Fig. 1). For sequences of half hitches $(\mathrm{S})$, the number of throws is not indicated because it are always 1 . If the passive thread is the same as in the previous knot, the combination is sliding; if active and passive treads are changed, the half hitch becomes blocking, as indicated by "b". Thus, SSSbSbSb indicates 5 half hitches, 2 sliding SS, followed by 3 blocking SbSbSb (Fig. 1E). Note that the active thread of the fourth half hitch is the same as in the first 2 half hitches.

\section{Study Design}

The aim of the present study was to evaluate the security of the various knot combinations used in surgery. Identical loops were tied around a $15-\mathrm{mm}$ plastic tube using different knot combinations. These loops were subsequently mounted similarly on the hooks of a digital dynamometer (IP90-DI; Impac Comercial e Tecnologia, São Paulo, Brazil) (Supplemental Fig. S1D and E) and tested at a speed of $200 \mathrm{~mm} /$ minute as described by Herrmann [17]. With increasing extension, either the knot combination slipped to open or the knot blocked and caused the suture to break. Thus, the first study endpoint was the force, in Newtons (N), at which the knot slipped to open or at which the suture broke. Breaking always occurred in or close to the knot. The unit of force as measured by a dynamometer is the Newton; $1 \mathrm{~N}$ is the force needed to accelerate $1 \mathrm{~kg}$ of mass at the rate of $1 \mathrm{~m} / \mathrm{s}^{2}$, or 1 $\left.\mathrm{N}=1 \mathrm{~kg} \cdot \mathrm{m} / \mathrm{s}^{2}\right)$. The unit of pressure is the Pascal $(1 \mathrm{~Pa}=1$ $\mathrm{N} / \mathrm{m}^{2}$ ), or $\mathrm{mmHg}$; their relative importance in sutures and knot security is unclear. Traction by the mesh on the knot following promontofixation and traction on the stitches after closing the abdominal fascia seem to be forces (ie Newtons). In surgery, forces on the abdominal wall and intra-abdominal pressures are related according to Pascal's law, as demonstrated by bursting pressures $[44,45]$.

The first knot combinations that we tested were combinations of 2 knots. For half knots, we tested 2 single-throw half knots (either symmetric H1H1s or asymmetric H1H1a), a double throw followed by a single- or double-throw half knot $(\mathrm{H} 2 \mathrm{H} 1 \mathrm{~s}, \mathrm{H} 2 \mathrm{H} 1 \mathrm{a}, \mathrm{H} 2 \mathrm{H} 2 \mathrm{~s}$, or $\mathrm{H} 2 \mathrm{H} 2 \mathrm{a})$ or a triple-throw half knot followed by a double-throw half knot $(\mathrm{H} 3 \mathrm{H} 2 \mathrm{~s}$ or $\mathrm{H} 3 \mathrm{H} 2 \mathrm{a}$ ). For half hitches, we tested a sliding (SS) or blocking ( $\mathrm{SSb}$ ) second half hitch.

We next investigated the effect of adding additional knots to the 2-knot bases. These additional knots included $+\mathrm{H} 1 \mathrm{a}$ for $\mathrm{H} 1 \mathrm{H} 1 \mathrm{a} ;+\mathrm{H} 1 \mathrm{~s},+\mathrm{H} 1 \mathrm{sH} 1 \mathrm{~s},+\mathrm{S}$, and $+\mathrm{SSb}$ for $\mathrm{H} 2 \mathrm{H} 1 \mathrm{~s}$; +H1a and $+\mathrm{SSb}$ for $\mathrm{H} 2 \mathrm{H} 1 \mathrm{a} ;+\mathrm{H} 2 \mathrm{a}$ and $+\mathrm{SSb}$ for $\mathrm{H} 2 \mathrm{H} 2 \mathrm{a} ;+\mathrm{H} 1 \mathrm{~s}$ and $+\mathrm{S}$ for $\mathrm{H} 3 \mathrm{H} 2 \mathrm{~s}$; $+\mathrm{H} 1 \mathrm{a}$ for $\mathrm{H} 3 \mathrm{H} 2 \mathrm{a}$; and $+\mathrm{S},+\mathrm{Sb},+\mathrm{SbSb}$, and $+\mathrm{SbSbSb}$ for SS. After finalizing the statistical analysis, we conducted exploratory experiments, which identified a sequence of 5 single-throw symmetric half knots and
$\mathrm{H} 2 \mathrm{H} 1 \mathrm{sH} 1 \mathrm{sSSb}$ as secure combinations (Fig. 2). Finally, we tested S2H1s, because a 2-throw half knot (H2) is easily transformed into a 2-throw half hitch (S2) by pulling on 1 thread only. Unfortunately, this is a frequent mistake made during endoscopic knot tying when performing the second half knot.

We did not evaluate how to increase the security of a first complex sliding/blocking knot as a Roeder, Duncan loop, Weston, or other with subsequent half hitches [30].

The suture material was dry $2-0$ polyglactin 910 . Findings were subsequently validated for wet $2-0$ polyglactin 910 and for 2-0 polyglecaprone 25 (US Pharmacopeia size) using selected knot combinations.

At least 40 combinations of knots (tied by the same surgeon) were tested to detect knot combinations that occasionally behaved differently. Forty knot combinations was considered the minimum, given that an incidence of 5\% to $10 \%$ would result in only 2 to 4 cases; using a Poisson approximation, the $95 \%$ confidence intervals (CIs) would be $0.6 \%$ to $18.0 \%$ and $2.5 \%$ to $25 \%$, respectively. Therefore, up to 120 knot combinations were evaluated for selected knots, because a $5 \%$ to $10 \%$ incidence using a binomial distribution would result in $95 \%$ CIs of $1.8 \%$ to $10.9 \%$ and $5.2 \%$ to $16.8 \%$, respectively [46]. A total of 2000 knot combinations were evaluated, comprising 1401 knots using dry polyglactin 910, 240 knots using wet 2-0 polyglactin 910, and 279 knots using dry 2-0 poliglecaprone (800 knots tied by Dr Romeo, 400 by Dr Rocha, 40 by Dr Fujimoto, 120 by Dr Asencio, 160 by Dr Fernandes, 120 by Dr Zomer, and 360 by Dr Kondo). These included $80 \mathrm{H} 2 \mathrm{H} 1 \mathrm{~s}, 120 \mathrm{H} 2 \mathrm{H} 1 \mathrm{sH} 1 \mathrm{~s}$, $80 \mathrm{H} 2 \mathrm{H} 1 \mathrm{sH} 1 \mathrm{sH} 1 \mathrm{~s}, 80 \mathrm{H} 2 \mathrm{H} 1 \mathrm{sS}$, and $81 \mathrm{H} 2 \mathrm{H} 1 \mathrm{sSSb}$ knots. In addition, $80 \mathrm{SSSb}$ and $80 \mathrm{SSSbSb}$ knots were tested using polyglactin, and $120 \mathrm{H} 2 \mathrm{H} 1 \mathrm{sH} 1 \mathrm{~s}, 80 \mathrm{H} 2 \mathrm{H} 1 \mathrm{sS}, 81 \mathrm{H} 2 \mathrm{H} 1 \mathrm{sSSb}$, and $80 \mathrm{H} 2 \mathrm{H} 2 \mathrm{aSSb}$ knots were tested using poliglecaprone.

\section{Knot Tying}

All testing was done under ambient conditions at Karl Storz South America, São Paulo, Brazil. The surgeons were experts in laparoscopic surgery and laparoscopic suturing instructors. All used the Romeo gladiator rule knot tying technique [47]. All sutures were done using a second-generation laparoscopic simulator (ETX A2 EVE; Prodelphus Surgical Simulators; Olinda, Pernambuco, Brazil), simulating the abdominal cavity. An artificial tissue mimicking real organic tissue (Tontarra Medizintechnik, Wurmlingen, Germany) lined the inner surface.

The knots were standardized as follows. A 12-cm-long, 15-mm-diameter orange tube was fixed to the artificial tissue on both sides (Supplemental Fig. S1C) over 3 sutures of $18 \mathrm{~cm}$, leaving one end $6 \mathrm{~cm}$ long and the other end $12 \mathrm{~cm}$ long. Following knot tying, the suture threads were cut at exactly $10 \mathrm{~mm}$. This permitted measurement of slight sliding of the knot while being sufficient to prevent a limited sliding of the suture loop from resulting in opening of the suture combination. The Karl Storz full HD imaging system (an Image 1 


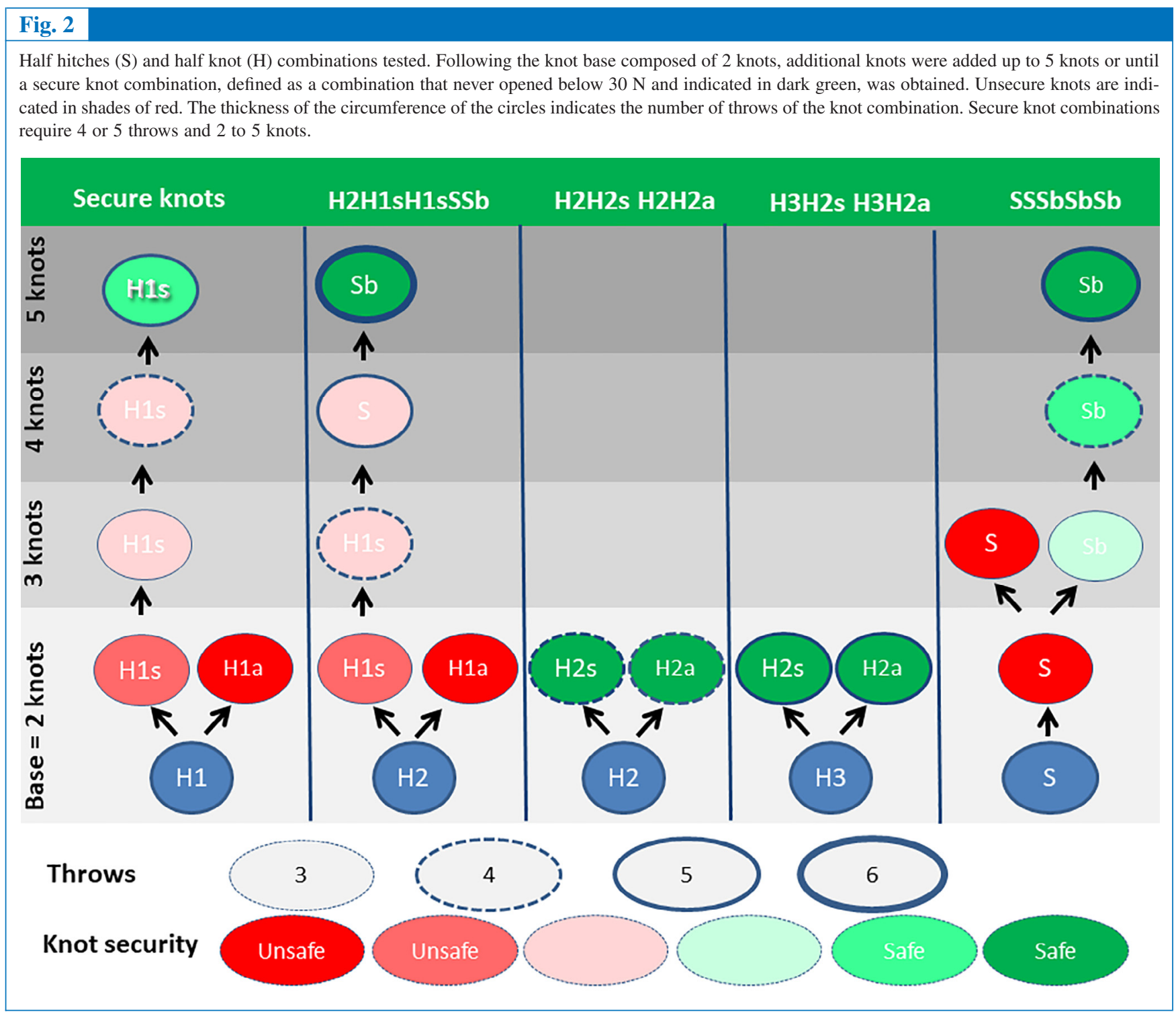

Hub HD and a 3-chip HD camera head; Karl Storz, Tüttlingen, Germany) (Supplemental Fig. S1A) and 2 Karl Storz needle holders (Karl Storz KOH macro needle holder) (Supplemental Fig. S1B) were used. To ascertain the accurate sequence of each knot combination, the knot sequences were controlled by the expert holding the camera.

\section{Statistics}

To evaluate the quality of the knots, arbitrary classifications were assigned for suture combination opening: $<1 \mathrm{~N}$, between 1 and $5 \mathrm{~N}$, between 6 and $10 \mathrm{~N}$, between 11 and $15 \mathrm{~N}$, between 16 and $30 \mathrm{~N}$, and $>30 \mathrm{~N}$. Openings at $<10 \mathrm{~N}$ are indicated in shades of red, because they are considered potentially clinically dangerous. Knots that never opened at $<30 \mathrm{~N}$ are indicated in shades of green, and are considered safe. Either these knots opened at forces $>30 \mathrm{~N}$ or the sutures broke without opening.
Statistical analyses were performed using SAS software (SAS Institute, Cary, NC). Differences in breaking strength were evaluated with the Student $t$ test and Wilcoxon ranksum test, and differences in opening of knot combinations were evaluated using the Mantel-Haenszel $\chi^{2}$ test. The effect of the suture material and of wet sutures was evaluated by analysis of variance and/or logistic regression (SAS proc logistic procedure).

\section{Results}

For 2 half knots, the quality of the knot base increased with the number of throws $(\mathrm{p}<.0001)$ and with the rotation (Figs. 2 and 3). Symmetric and asymmetric sequences of half knots-H1H1s, H1H1a, H2H1s, H2H1a, H2H2s, H2H2a, $\mathrm{H} 3 \mathrm{H} 2 \mathrm{~s}$, and $\mathrm{H} 3 \mathrm{H} 2 \mathrm{a}$-resulted in $92 \%, 0 \%, 93.2 \%, 17.5 \%$, $97.5 \%, 100 \%, 100 \%$, and $100 \%$ safe knot combinations, respectively, and in $5 \%, 95 \%, 5 \%, 72.2 \%, 0 \%, 0 \%, 0 \%$, and 


\section{Fig. 3}

Opening and breaking of different knot combinations using dry 2-0 polyglactin 910 (PP). In the upper graph, breaking strengths of knot combinations are indicated (data are mean $\pm \mathrm{SD}$ ). Knots are grouped as a combination of 2 flat base knots $(\mathrm{H} 1 \mathrm{H} 1, \mathrm{H} 2 \mathrm{H} 1, \mathrm{H} 2 \mathrm{H} 2$, and $\mathrm{H} 3 \mathrm{H} 2$ ), symmetric and asymmetric (indicated in green and yellow, respectively, with a black border) and as combinations of half hitches. Each knot combination is followed by a series of additional knots to improve the knot combination. The lower graph indicates opening at $<1 \mathrm{~N},<6 \mathrm{~N},<11 \mathrm{~N},<16 \mathrm{~N},<31 \mathrm{~N},>30 \mathrm{~N}$, or break.
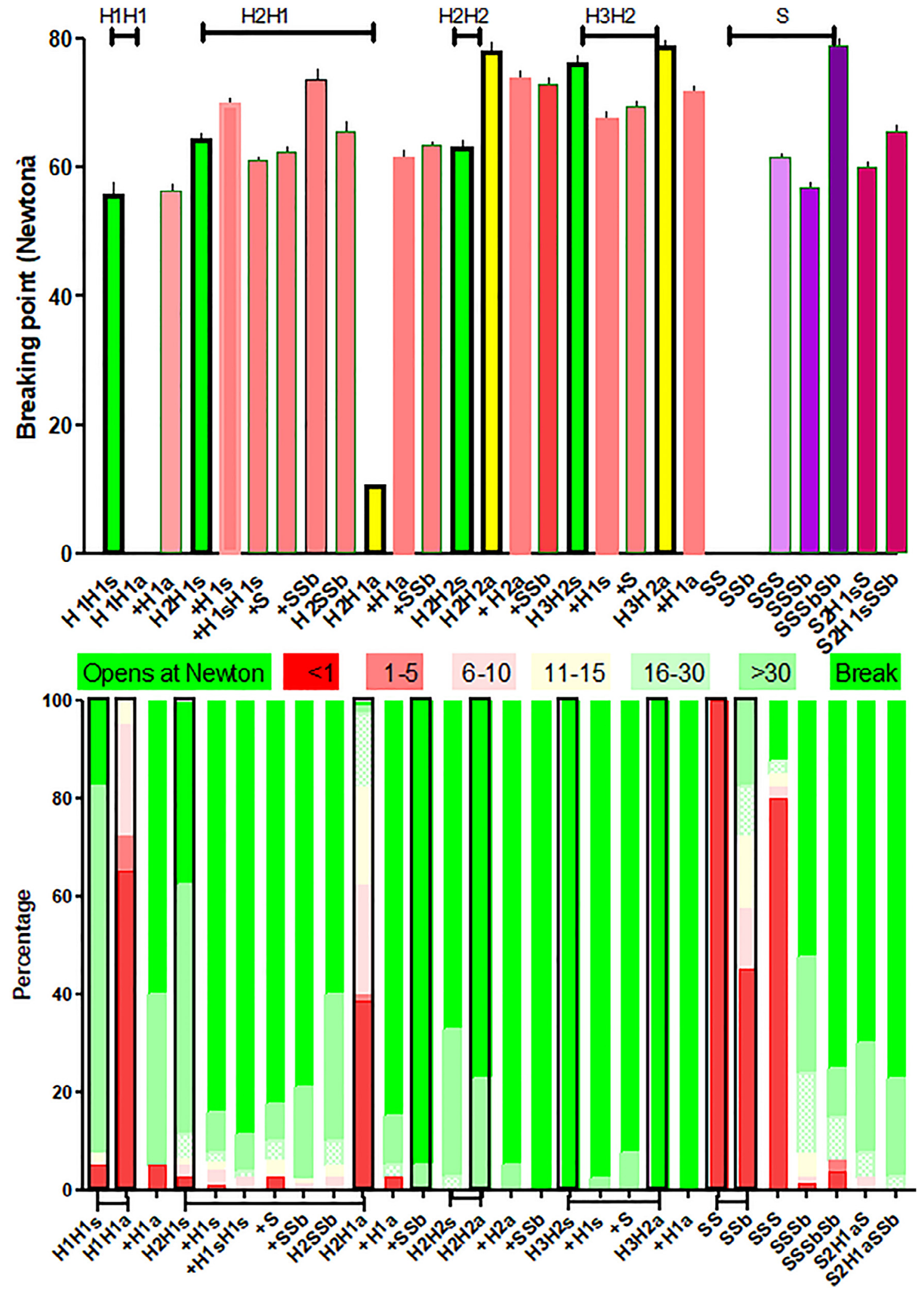


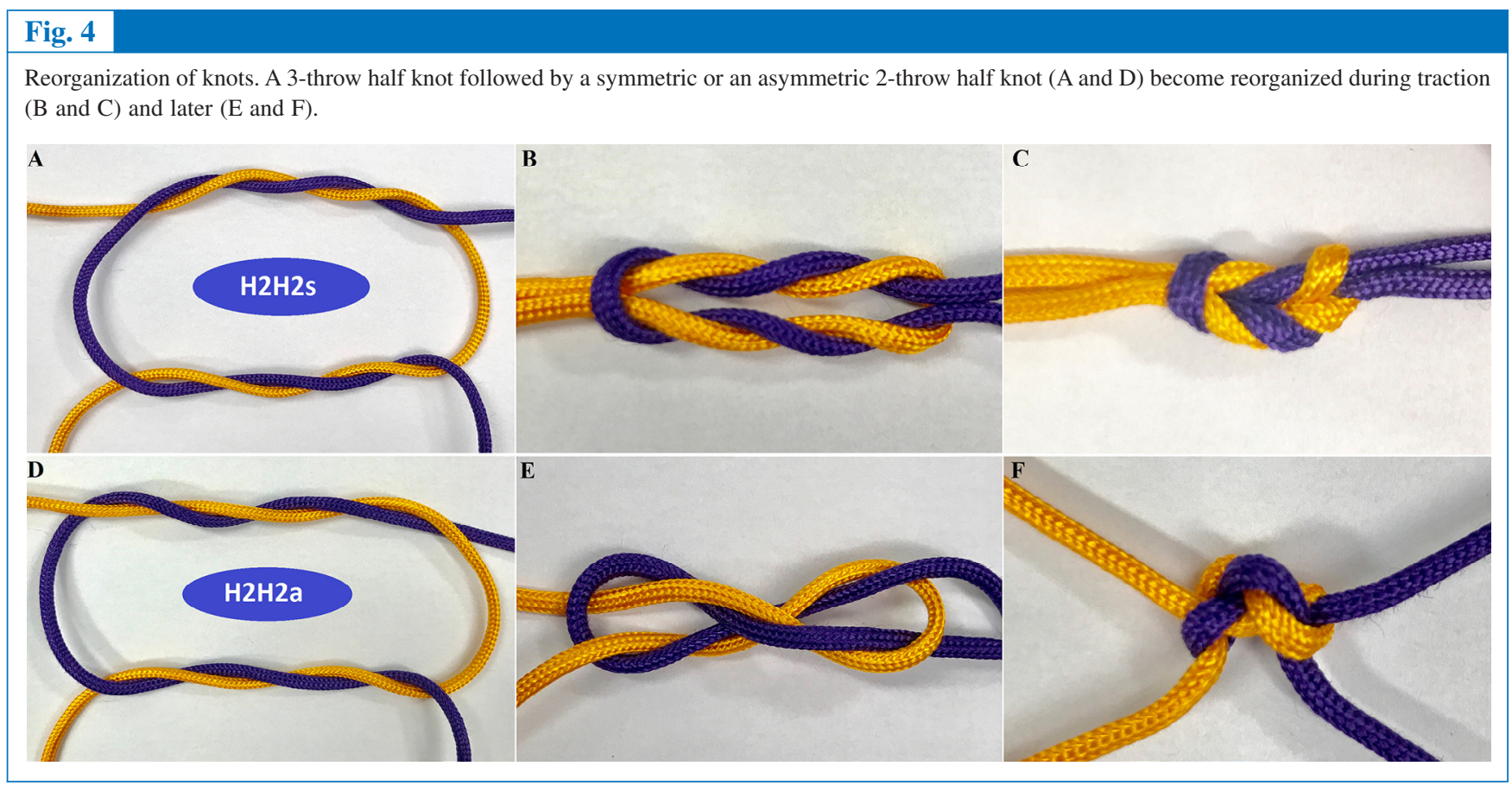

$0 \%$ dangerous knot combinations, respectively. $\mathrm{H} 1 \mathrm{H} 1 \mathrm{a}$ and $\mathrm{H} 2 \mathrm{H} 1 \mathrm{a}$, asymmetric sequences performed much worse than symmetric knots (H1H1s and H2H1s) ( $<.0001$ for both); However, asymmetric $\mathrm{H} 2 \mathrm{H} 2 \mathrm{a}$ and $\mathrm{H} 3 \mathrm{H} 2 \mathrm{a}$ sequences gave similar or slightly better (NS) results than symmetric knot combinations $(\mathrm{H} 2 \mathrm{H} 2 \mathrm{~s}$ and $\mathrm{H} 3 \mathrm{H} 2 \mathrm{~s})$ with $100 \%$ safe knots (Fig. 3).

The unexpected $5 \%$ potentially dangerous knots of the $\mathrm{H} 2 \mathrm{H} 1 \mathrm{~s}$ combination could not be recuperated completely by adding 1 or 2 additional symmetric 1-throw half knots (Figs. 2 and 4). Although the results improved ( $\mathrm{p}<.0001$ for both), $3 \%$ and $2 \%$ dangerous knots, remained, respectively. Surprised by these results, we increased the number of $\mathrm{H} 2 \mathrm{H} 1 \mathrm{sH} 1 \mathrm{~s}$ knots to 120 and the number of $\mathrm{H} 2 \mathrm{H} 1 \mathrm{~s}$ and $\mathrm{H} 2 \mathrm{H} 1 \mathrm{sH} 1 \mathrm{sH} 1 \mathrm{~s}$ to 80 . This confirmed and validated $(\mathrm{p}<.05)$ the observations, because the lower $95 \%$ CIs for 120 and 280 were $2.7 \%$ and $2.8 \%$, respectively. Adding a half hitch (S) or 2 blocking half hitches ( $\mathrm{SSb}$ ) also improved the combination $(\mathrm{p}<.0001)$, but $2.5 \%$ and $1.2 \%$ dangerous knots persisted, respectively. The $60 \%$ dangerous combination of $\mathrm{H} 2 \mathrm{H} 1 \mathrm{a}$ improved by adding a third asymmetric single-throw half knot, but $5 \%$ dangerous knots remained.

The already excellent symmetric or asymmetric $\mathrm{H} 2 \mathrm{H} 2 \mathrm{com}-$ bination slightly improved with an additional half knot $(\mathrm{p}=.02)$ or 2 additional blocking half hitches $(\mathrm{p}=.0015)$. All H2H2 and $\mathrm{H} 3 \mathrm{H} 2$ combinations resulted in safe knots, however. Remarkably, only the $\mathrm{H} 3 \mathrm{H} 2$ combinations never opened; they remained obviously stable after an additional asymmetric single-throw half knot.

Two or 3 half hitches on the same thread (SS and SSS, respectively) known as sliding knots, opened at $<10 \mathrm{~N}$ in $100 \%$ and $82.545 \%$ of knots, respectively. Surprisingly, $12.5 \%$ of these triple sliding half hitches did block. Two blocking half hitches (SSb) still opened at $<10 \mathrm{~N}$ in $57.5 \%$. A combination of 3 (SSSb) or 4 (SSSbSb) half hitches, 2 sliding and 1 or 2 blocking resulted in only $75 \%$ and $86 \%$ safe knots, respectively, with multifilament sutures. A combination of 5 half hitches, 2 sliding and 3 blocking (SSSbSbSb), resulted in $100 \%$ safe knots even with a monofilament sutures.

The accidentally made S2H1s with one additional half hitch knots were potentially dangerous in $2.5 \%$ of cases. The addition of 2 more blocking half hitches resulted in safe knots.

Reorganization refers to suture configuration changes that occur while a knot is tightened. Some sutures become twisted and various angles can promote stabilization or destabilization of the knot combination. This process is not yet well understood but has been reliably observed in vivo and in suture tying labs. We suspect that in addition to the knot combination, the type of suture and the tying force applied to the knot may influence reorganization and knot security. Because we do not completely understand this process but have consistently observed it, we demonstrate reorganization visually in Figure 4. These angulation forces can explain why the suture always breaks in or close to the knot (Fig. 4 and Supplemental Fig. 1F). This also shows that breaking forces are lower than the breaking strengths of the sutures. Angulation or damage also explains why different knot combinations break at different forces. However, the forces needed to break a knot are constant for each combination, as evidenced by the small standard deviation values; thus, all, even small, differences are highly significant $(\mathrm{p}<.0001)$. Knot reorganization (Fig. 2) and angulation explain why some combinations apparently break around $50 \mathrm{~N}$ to $60 \mathrm{~N}$ and others break around $60 \mathrm{~N}$ to 
$80 \mathrm{~N}$. Therefore, it is not surprising that combinations of half hitches have highly significantly lower breaking forces than half knot combinations. This also explains why asymmetric $\mathrm{H} 2 \mathrm{H} 2$ and asymmetric $\mathrm{H} 3 \mathrm{H} 2$ with a broad base have significantly higher breaking strength than symmetric combinations (Fig. 4).

As expected, knot security increases with the total number of throws $(\mathrm{p}<.0001)$; however, all $100 \%$ safe knot combinations require at least $4(\mathrm{H} 2 \mathrm{H} 2)$, but generally 5 , throws.

Wet 2-0 polyglactin 910 knot combinations performed slightly worse than dry 2-0 polyglactin $910(\mathrm{p}=.0003)$, and $2-0$ polyglecaprone sutures performed slightly better $(\mathrm{p}<.04)$ than 2-0 polyglactin 910 (Fig. 5). However, for the knot combinations tested, these small differences had no significant effect on the percentage of dangerous or safe knots.

\section{Discussion}

Our present results confirm common knowledge such as the instability of a combination of 2 asymmetric knots, either 2 single-throw half knots $(\mathrm{H} 1 \mathrm{H} 1 \mathrm{a})$ or a double-throw $+\mathrm{a}$ single-throw half knot (H2H1a) (Fig. 2). They also confirm that 2 (SS) and 3 (SSS) half hitches are sliding. Some of these results are surprising and new. Combinations of 2, 3, or 4 symmetric half knots-the classical surgical knots $\mathrm{H} 2 \mathrm{H} 1 \mathrm{~s}$, $\mathrm{H} 2 \mathrm{H} 1 \mathrm{sH} 1 \mathrm{~s}$, and $\mathrm{H} 2 \mathrm{H} 1 \mathrm{sH} 1 \mathrm{sH} 1 \mathrm{~s}$, which are widely used in surgery because they are considered stable - were found to be occasionally unsafe. Indeed, these knots opened with $<1$ $\mathrm{N}$ in $5 \%, 3.8 \%$, and $2.5 \%$ of cases, respectively. The clinical significance of knot combinations that slide open between $1 \mathrm{~N}$ and $10 \mathrm{~N}$, between $10 \mathrm{~N}$ and $15 \mathrm{~N}$, and between $16 \mathrm{~N}$ and $30 \mathrm{~N}$ is not clear, and an investigation of the resistance required after various types of surgery is warranted. Our findings only demonstrate that these knots are not as stable as once generally thought. Additional knots obviously improve final stability. It is astonishing that even the addition of a fourth symmetric single-throw half knot did not eliminate potentially dangerous knots. Only the combination of 2 doublethrow half knots $(\mathrm{H} 2 \mathrm{H} 2)$ or of a triple-throw half knot and a double-throw half knot $(\mathrm{H} 3 \mathrm{H} 2)$ proved sufficiently stable to not open at $<30 \mathrm{~N}$ whether symmetric or asymmetric. A similar picture emerged for half hitch combinations. As expected, 3 half hitches, 2 sliding and 1 blocking, are not secure. A safe half hitch combination requires 5 half hitches, of which the last 3 are blocking.

Although not all combinations were tested in sufficient numbers for statistical significance when opening at a low percentage, the confidence limits of the "surgical knots" and the overall consistently emerging picture of 2000 knots tested allow us to conclude that the occasional dangerous knot combination is a reality. Whether this might be related to the strength of tying the individual knots is unclear. Regardless, the clinical implications require further investigation. When analyzing the total number of throws in knot combinations, a total of 5 or 6 throws seems to be the minimum for a stable knot, except for the 4 throws in the $\mathrm{H} 2 \mathrm{H} 2$ knot (Fig. 2).

Studying the reorganization of knot combinations (Fig. 4) during traction with angulation and damage of the suture is important to understanding their behavior. It explains why a sequence of 3 sliding half hitches did not always result in a sliding knot. Inspection of the knot combination after breaking confirmed that the knots had been rearranged into a blocking sequence. Knot reorganization also explains why asymmetric knot combinations, such as H1H1a and H2H1a, were unstable. Reorganization also explains why the broad bases of asymmetric $\mathrm{H} 2 \mathrm{H} 2 \mathrm{a}$ and $\mathrm{H} 3 \mathrm{H} 2 \mathrm{a}$ knots were slightly better than symmetric combinations (Fig. 2). Reorganization also explains why knot tails became shorter before breaking. Because this occurred only at forces $>30 \mathrm{~N}$, it is not considered clinically important, at least not in gynecologic surgery. These findings confirm the results published by Amortegui and Restrepo [15] showing that only $70 \%$ of SSSS knots and $60 \%$ of SSSSS knots tied by laparoscopy opened. Given our scrutiny during knot tying, we suggest that the reorganization was caused by the opening forces; however, we cannot exclude the possibility that we missed the accidental rearrangement or destabilization of the first half knot into a half hitch when tying the second half knot.

These data emphasize the need for all surgeons to understand and master the correct combinations of surgical knots [19]. In addition, we should realize that some knot combinations lead more often to mistakes, and that the force of tying each individual knot is important [48]. Indeed, suturing and tying knots are essential skills in most surgical procedures for tissue apposition and hemostasis [1]. When a suture fails, the consequences may be disastrous, with possibly massive bleeding, evisceration [21], and vaginal vault dehiscence.

The extrapolation of these findings to clinical implications should be done with caution. The only $100 \%$ reliable knots that never open at $<30 \mathrm{~N}$ are $\mathrm{H} 3 \mathrm{H} 2$ or $\mathrm{H} 2 \mathrm{H} 2$, symmetric or asymmetric, or 5 half hitches with 3 blocking sequences or a solid base of 2 symmetric half knots secured by 2 blocking half hitches (Fig. 2). This is especially relevant in gynecologic laparoscopic surgery, where a series of 3 half hitches with only 1 blocking sequence is frequently used [49]. The $\mathrm{H} 3 \mathrm{H} 2$ and $\mathrm{H} 2 \mathrm{H} 2$ combinations have the additional advantage of remaining stable regardless of whether they are symmetric or asymmetric and of not changing behavior with surgical mistakes. Moreover, secure knots have the advantage of remaining safe when the tails are cut short. We expected that our results can be generalized, because they did not vary significantly with the type of suture or with wet sutures, but this needs to be confirmed. The extrapolation to surgical practice should be done carefully.

The definition of knot security as a knot combination that does not untie or slip to open before the suture line breaks [1,5] should be updated. Many knot combinations open at forces $>30 \mathrm{~N}$, which we suggest is not clinically relevant. Clinical data are needed to judge the in vivo forces on, for example, the abdominal wall during laughing, coughing, straining, 
Fig. 5

Strengths when breaking (upper graph) and percentage of knots that open or break (lower graph) for different knot combinations as indicated. Knot combinations were performed with dry 2-0 polyglactin 910 (PP), dry 2-0 polyglecaprone (CP) and wet 2-0 PP. In the upper graph, the latter are indicated in green, blue, and red, respectively. In the lower graph, it is indicated whether knot combinations open at $<1 \mathrm{~N},<6 \mathrm{~N},<11 \mathrm{~N},<16 \mathrm{~N},<31 \mathrm{~N},>30 \mathrm{~N}$, or break. Dry and wet PP have a black and red border, respectively.

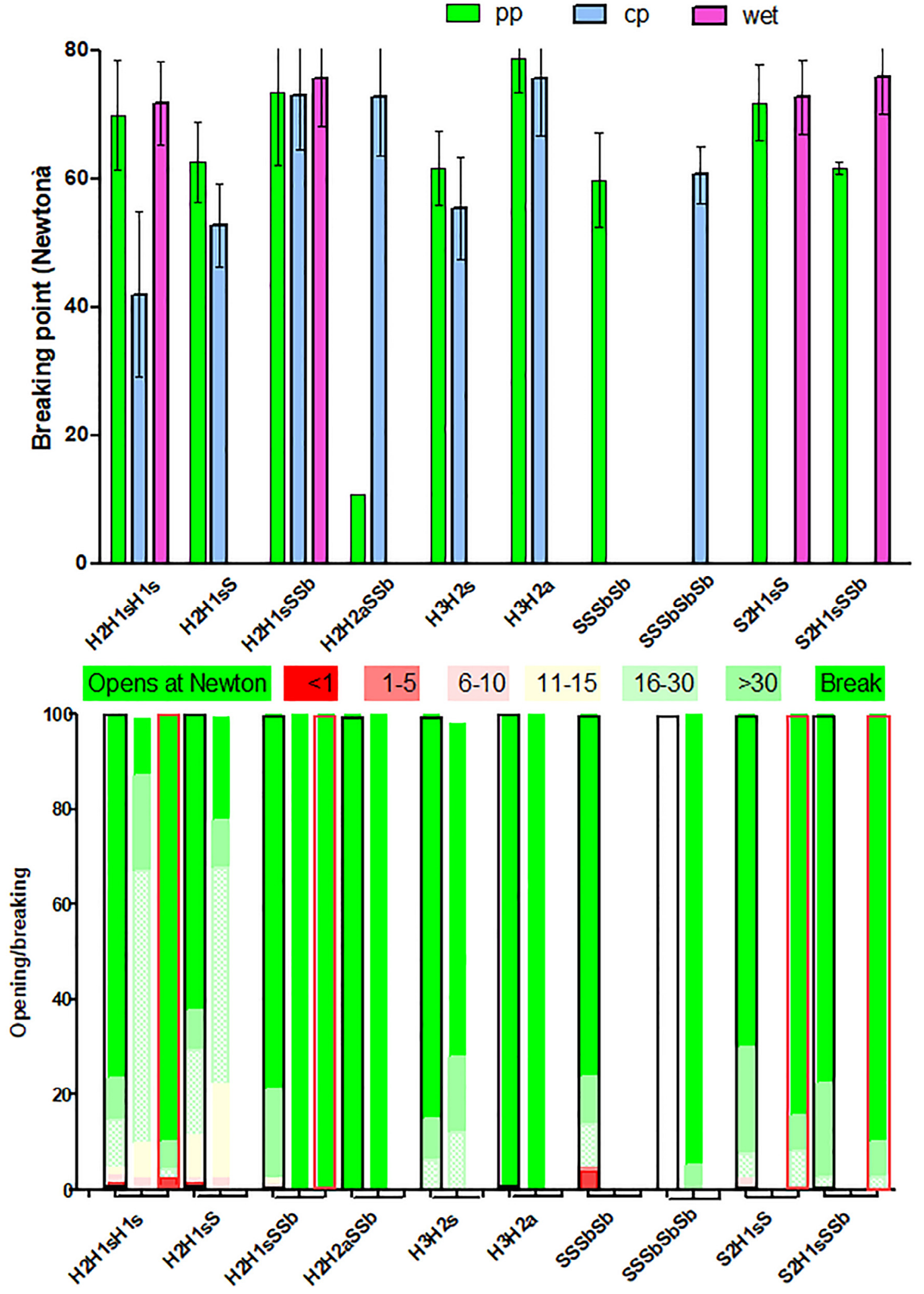


sneezing, and physical activity. Today we only speculate that opening at $<10 \mathrm{~N}$ might be dangerous. This also applies to the required tensile strength of a suture. Considering that the breaking forces of the 2.0 sutures used are between $60 \mathrm{~N}$ and $80 \mathrm{~N}$, along with the assumption that a suture retains at least $50 \%$ of its initial tensile strength after 1 week, it seems logical to suggest that the actual thickness of the sutures used is based on prudence and experience [50], and that a much thinner suture might prove to be equally safe; however, for thinner sutures, angulation and lower breaking forces might become an issue. The observation of sutures that open under little or no force is especially important when considering running sutures. Finally, a 100\% secure and stable knot will allow the suture tails to be cut short. Short tails, together with the use of thinner suture material, will at least reduce knot volume [49], and the duration of the inflammatory reaction needed for hydrolyzation or resorption of sutures. This is expected to reduce postoperative adhesion formation, which increases when sutures are not resorbed completely within 5 days after surgery [51].

In conclusion, the safety of the various knot combinations tested was not what we expected, with low percentages of many of the currently widely used combinations opening at random under little or no force. Only the $\mathrm{H} 3 \mathrm{H} 2$ and $\mathrm{H} 2 \mathrm{H} 2$ combinations or at least 5 half hitches with 3 in blocking sequences can be considered stable and always safe combinations. These findings can help guide training and surgical approach. Of course, our observations need to be extended and confirmed for other suture materials, and should be considered in future suture material development. Indeed, all suture material should be evaluated for knot combination security, given that it cannot be taken for granted that monofilament and multifilament sutures, very thin and thicker or made of various materials, will always behave similarly.

\section{Acknowledgments}

We thank Mauricio Abrao, Paulo Ayroza Ribeiro, Helizabet Salomão and Luciano Gibran (São Paulo, Brazil), Audrey Tsunoda (Curitiba, Brazil), Nucelio Lemos (Toronto, Canada), Victor Gomel (Vancouver, Canada), Revaz Botchorishvili and Benoit Rabischong (Clermont, France), Mario Malzoni (Rome, Italy), Riccardo Zaccoletti (Verona, Italy), Antonio Setubal (Lisboa, Portugal), and Juan Gilabert (Valencia, Spain) for input, comments, and discussion. We also thank Karl Storz, Tüttlingen, Germany for allowing the use of the Storz training center in São Paulo and providing the laparoscopic equipment.

\section{Supplementary Data}

Supplementary data related to this article can be found at https://doi.org/10.1016/j.jmig.2018.01.032.

\section{References}

1. Marturello DM, McFadden MS, Bennett RA, Ragetly GR, Horn G. Knot security and tensile strength of suture materials. Vet Surg. 2014;43:7379.

2. Ashley CW. The Ashley Book of Knots. New York: Doubleday; 1944.

3. Dinsmore RC. Understanding surgical knot security: a proposal to standardize the literature. J Am Coll Surg. 1995;180:689-699.

4. Price PB. Stress, strain and sutures. Ann Surg. 1948;128:408420.

5. Burkhart SS, Wirth MA, Simonich M, Salem D, Lanctot D, Athanasiou K. Knot security in simple sliding knots and its relationship to rotator cuff repair: how secure must the knot be? Arthroscopy. 2000;16:202207.

6. Barber FA, Herbert MA, Beavis RC. Cyclic load and failure behavior of arthroscopic knots and high strength sutures. Arthroscopy. 2009;25:192-199.

7. Ilahi OA, Younas SA, Alexander J, Noble PC. Cyclic testing of arthroscopic knot security. Arthroscopy. 2004;20:62-68.

8. Kim SH, Yoo JC, Wang JH, Choi KW, Bae TS, Lee CY. Arthroscopic sliding knot: how many additional half hitches are really needed? Arthroscopy. 2005;21:405-411.

9. Hanna GB, Frank TG, Cuschieri A. Objective assessment of endoscopic knot quality. Am J Surg. 1997;174:410-413.

10. Franz DA, Batra EK, Morgan RF, Edlich RF. A portable tensiometer for assessing knot-tying technique. Orthopedics. 1995;18:555558.

11. Hill SW, Chapman CR, Adeeb S, Duke K, Beaupre L, Bouliane MJ. Biomechanical evaluation of the Nice knot. Int J Shoulder Surg. 2016;10:15-20.

12. Ilahi OA, Younas SA, Ho DM, Noble PC. Security of knots tied with ethibond, fiberwire, orthocord, or ultrabraid. Am J Sports Med. 2008;36:2407-2414

13. Schaaf O, Glyde M, Day RE. In vitro comparison of secure Aberdeen and square knots with plasma- and fat-coated polydioxanone. Vet Surg. 2010;39:553-560.

14. Schubert DC, Unger JB, Mukherjee D, Perrone JF. Mechanical performance of knots using braided and monofilament absorbable sutures. Am J Obstet Gynecol. 2002;187:1438-1440, discussion 14411442.

15. Amortegui JD, Restrepo H. Knot security in laparoscopic surgery. A comparative study with conventional knots. Surg Endosc. 2002;16:15981602.

16. Dorsey JH, Sharp HT, Chovan JD, Holtz PM. Laparoscopic knot strength: a comparison with conventional knots. Obstet Gynecol. 1995;86(4 Pt 1):536-540.

17. Herrmann JB. Tensile strength and knot security of surgical suture materials. Am Surg. 1971;37:209-217.

18. Kadirkamanathan SS, Shelton JC, Hepworth CC, Laufer JG, Swain CP. A comparison of the strength of knots tied by hand and at laparoscopy. J Am Coll Surg. 1996;182:46-54.

19. Johnson AJ, Stulting RD. Knot-tying principles and techniques. In: Macsai MS, editor. Ophthalmic Microsurgical Suturing Techniques. New York: Springer; 2007, 21-28.

20. Sedlack JD, Williams VM, DeSimone J, Page D, Ghosh BC. Laparoscopic knot security. Surg Laparosc Endosc. 1996;6:144146.

21. Thacker JG, Rodeheaver G, Moore JW, et al. Mechanical performance of surgical sutures. Am J Surg. 1975;130:374-380.

22. Trimbos JB, Van Rijssel EJ, Klopper PJ. Performance of sliding knots in monofilament and multifilament suture material. Obstet Gynecol. 1986;68:425-430.

23. Trimbos JB, Klopper PJ. Knot security of synthetic absorbable suture material; a comparison of polyglycolic acid and polyglactin-910. Eur J Obstet Gynecol Reprod Biol. 1985;19:183-190.

24. Trimbos JB. Security of various knots commonly used in surgical practice. Obstet Gynecol. 1984;64:274-280. 
25. Ilahi OA. Shortcuts in arthroscopic knot tying. Am J Sports Med. 2013;41:NP8.

26. Lee YH, Kim MJ, Chong GO, Hong DG, Lee J, Lee YS. YS knot: a new technique for a tension-controlled slip knot using a trocar. Obstet Gynecol Sci. 2015;58:171-174.

27. Huang E, Chern H, O'Sullivan P, et al. A better way to teach knot tying: a randomized controlled trial comparing the kinesthetic and traditional methods. Am J Surg. 2014;208:690-694.

28. Kim SH, Glaser D, Doan J, et al. Loop securities of arthroscopic slidingknot techniques when the suture loop is not evenly tensioned. Arthroscopy. 2013;29:1380-1386.

29. Alzacko SM, Majid OW. Security loop" tie: a new technique to overcome loosening of surgical knots. Oral Surg Oral Med Oral Pathol Oral Radiol Endod. 2007;104:e1-e4.

30. Jo CH, Lee JH, Kang SB, et al. Optimal configuration of arthroscopic sliding knots backed up with multiple half hitches. Knee Surg Sports Traumatol Arthrosc. 2008;16:787-793.

31. Lo IK, Burkhart SS, Chan KC, Athanasiou K. Arthroscopic knots: determining the optimal balance of loop security and knot security. Arthroscopy. 2004;20:489-502.

32. Boettcher M, Boettcher J, Mietzsch S, Krebs T, Bergholz R, Reinshagen $\mathrm{K}$. The spaced learning concept significantly improves training for laparoscopic suturing: a pilot randomized controlled study. Surg Endosc. 2018;32:154-159.

33. Gershuni V, Woodhouse J, Brunt LM. Retention of suturing and knottying skills in senior medical students after proficiency-based training: results of a prospective, randomized trial. Surgery. 2013;154:823829, discussion 829-830.

34. Botden SM, de Hingh IH, Jakimowicz JJ. Suturing training in Augmented Reality: gaining proficiency in suturing skills faster. Surg Endosc. 2009;23:2131-2137.

35. Van Sickle KR, Ritter EM, Baghai M, et al. Prospective, randomized, double-blind trial of curriculum-based training for intracorporeal suturing and knot tying. J Am Coll Surg. 2008;207:560-568.

36. Kothari SN, Kaplan BJ, DeMaria EJ, Broderick TJ, Merrell RC. Training in laparoscopic suturing skills using a new computer-based virtual reality simulator (MIST-VR) provides results comparable to those with an established pelvic trainer system. J Laparoendosc Adv Surg Tech A. 2002;12:167-173.

37. Horeman T, Blikkendaal MD, Feng D, et al. Visual force feedback improves knot-tying security. J Surg Educ. 2014;71:133-141.
38. Blikkendaal MD, Twijnstra AR, Pacquee SC, et al. Vaginal cuff dehiscence in laparoscopic hysterectomy: influence of various suturing methods of the vaginal vault. Gynecol Surg. 2012;9:393-400.

39. Zapardiel I, Zanagnolo V, Peiretti M, Maggioni A, Bocciolone L. Avoiding vaginal cuff dehiscence after robotic oncological surgery: reliable suturing technique. Int J Gynecol Cancer. 2010;20:1264-1267.

40. Shin SJ, Chung H, Kwon SH, Cha SD, Cho CH. New suturing technique for robotic-assisted vaginal cuff closure during single-site hysterectomy. J Robot Surg. 2017;11:139-143.

41. King CR, Donnellan N, Guido R, Ecker A, Althouse AD, Mansuria S. Development and validation of a laparoscopic simulation model for suturing the vaginal cuff. Obstet Gynecol. 2015;126(Suppl 4):27S$35 \mathrm{~S}$.

42. Slieker JC, Daams F, Mulder IM, Jeekel J, Lange JF. Systematic review of the technique of colorectal anastomosis. JAMA Surg. 2013;148:190201.

43. Kondo W, Zomer MT, Hayashi RM, Fernandes LF, Fujimoto C, Romeo A. Different blocking sequences performed by laparoscopy. J Minim Invasive Gynecol. 2018;25:773.

44. Cobb WS, Burns JM, Kercher KW, Matthews BD, James Norton H, Todd Heniford B. Normal intraabdominal pressure in healthy adults. $J$ Surg Res. 2005;129:231-235.

45. Seror D, Nissan A, Spira RM, Feigin E, Udassin R, Freund HR. Comparison of bursting pressure of abdominal wall defects repaired by three conventional techniques. Am Surg. 2003;69:978-980.

46. Pezzullo JC. Exact binomial and poisson confidence intervals. Revised 2009. Available at: http://statpages.info/confint.html. Accessed March 4, 2018.

47. Liceaga A, Fernandes LF, Romeo A. Romeo's Gladiator Rule: Knots, Stitches, and Knot Tying Techniques: A Tutorial Based on a Few Simple Rules. Tuttlingen, Germany: Endo Press; 2013.

48. Ching SS, Mok CW, Koh YX, Tan SM, Tan YK. Assessment of surgical trainees' quality of knot-tying. J Surg Educ. 2013;70:48-54.

49. Ivy JJ, Unger JB, Hurt J, Mukherjee D. The effect of number of throws on knot security with nonidentical sliding knots. Am J Obstet Gynecol. 2004;191:1618-1620.

50. Haxton $\mathrm{H}$. The influence of suture materials and methods on the healing of abdominal wounds. Br J Surg. 1965;52:372-375.

51. Koninckx PR, Gomel V, Ussia A, Adamyan L. Role of the peritoneal cavity in the prevention of postoperative adhesions, pain, and fatigue. Fertil Steril. 2016;106:998-1010. 